\title{
Fisheries Production: Management Institutions, Spatial Choice, and the Quest for Policy Invariance
}

Matthew N. Reimer, University of Alaska Anchorage; Joshua K. Abbott, Arizona State University; and James E. Wilen, University of California, Davis

\begin{abstract}
A B S T R A C T
The fishery-dependent data used to estimate fishing production technologies are shaped by the incentive structures that influence fishermen's purposeful choices across their multiple margins of production. Using a combination of analytical and simulation methods, we demonstrate how market prices and regulatory institutions influence a dominant short-run margin of production - the deployment of fishing time over space. We show that institutionally driven spatial selection leads to only a partial exploration of the full production set, yielding poorly identified estimates of production possibilities outside of the institutionally dependent status quo. The implication is that many estimated fisheries production functions suffer from a lack of policy invariance and may yield misleading predictions for even the most short-run of policy evaluation tasks. Our findings suggest that accurate assessment of the impacts of a policy intervention requires a description of the fishing production process that is sufficiently structural so as to be invariant to institutional changes.
\end{abstract}

Key words: Policy evaluation, production function, fisheries, policy invariance, location choice, simulation. JEL Codes: D24, Q22.

\section{INTRODUCTION}

The specification of fishing production technology plays a critical role in informing fisheries policy. Empirical production models - of both the primal and dual varieties - are used to assess technical efficiency (e.g., Kirkley, Squires, and Strand 1995; Flores-Lagunes, Horrace, and Schnier 2007), measure excess capacity in limited-entry regimes (e.g., Felthoven 2002; Felthoven, Horrace, and Schnier 2009; Horrace and Schnier 2010), assess evidence of technical change (e.g., Squires and Vestergaard 2013a,b) and skipper skill (e.g., Kirkley and Squires 1998; Squires and Kirkley 1999; Alvarez and Schmidt 2006), predict the effects of input controls (e.g., Squires 1987a; Dupont 1991), and examine the potential for consolidation (e.g., Weninger and Waters 2003; Weninger 2008; Lian, Singh, and Weninger 2010) and substitution across multiple species (e.g., Squires 1987b; Squires and Kirkley 1991; Squires, Alauddin, and Kirkley 1994; Squires and

Matthew N. Reimer is an assistant professor, Institute of Social and Economic Research, Department of Economics and Public Policy, University of Alaska Anchorage, 3211 Providence Drive, Anchorage, AK 99508 USA (email: mreimer2@alaska.edu). Joshua K. Abbott is an associate professor, School of Sustainability, Global Institute of Sustainability, and Center for Environmental Economics and Sustainability Policy, Arizona State University, P.O. Box 875502, Tempe, AZ, 85287 USA (joshua.k.abbott@ asu.edu). James E. Wilen is a professor, Department of Agricultural and Resource Economics, University of California, Davis, 2116 Social Science \& Humanities, One Shields Avenue, Davis, CA, 95616 USA wilen@primal.ucdavis.edu

We thank a number of individuals for helpful comments, including Alan Haynie and Martin Smith, and three anonymous referees, as well as seminar participants at UC Davis, University of Washington, University of Alaska Fairbanks, and University of Alaska Anchorage, as well as IIFET 2012, NAAFE 2013, and AERE 2013 meetings.

Received May 11, 2016; Accepted November 18, 2016; Published online January 27, 2017. http://dx.doi.org/10.1086/690678

Marine Resource Economics, volume 32, number 2. (c) 2017 MRE Foundation, Inc. All rights reserved. $0738-1360 / 2017 / 3202-0003 \$ 10.00$ 
Kirkley 1996; Pascoe, Koundouri, and Bjørndal 2007; Pascoe, Punt, and Dichmont 2010) in the wake of output controls or multispecies individual transferable quotas (ITQs).

Much empirical analysis of fisheries simplifies the fishing production process by collapsing context-specific micro-margins into aggregated inputs. For example, empirical work in fisheries typically describes catch as a function of aggregated fixed inputs such as vessel length, tonnage, engine size, and gear type, and variable inputs such as crew size, fishing time, and fuel consumption. While such representations are an improvement over the single-index model of "effort" (Squires 1987a), we argue that the production process of fishing cannot be easily reduced to such a simple representation. Within the time horizon of a fishing season, fishing is primarily a process of deciding how to deploy fixed inputs over time and space given imperfect knowledge of the spatiotemporal dynamics of a fugitive resource. The answers to the questions "When?", "Where?", and "How long?" to allocate gear dominate fishermen's decision processes. Many of the traditionally included variable inputs in fishing production models are thus not direct choice variables for fishermen; rather, they are outcomes of fundamental decisions over the spatial and temporal deployment of fishing gear. Moreover, the profit or utility-maximizing behavior of fishermen and the incentives presented by markets and fisheries management institutions exert a selection effect upon fishermen's decisions over the seascape. The result of this spatiotemporal selection may be a selective and sparse "sampling" from the overall production set, yielding poorly identified estimates of production tradeoffs outside of the sampled region in inputoutput space.

The implications of this perspective on the fisheries production process are important for fisheries policy evaluation. If fishermen's spatiotemporal choices are shaped by the incentives inherent in management institutions, then the estimated a priori aggregate fishing production relationship is unlikely to be stable to interventions in management. Thus, conventional aggregate fishing production models do not identify policy invariant parameters and ultimately fail the Lucas (1976) critique. The importance of the Lucas critique to fisheries modeling is not new; economists have long understood that non-marginal institutional or market changes may induce fishermen to dramatically adapt their use of labor and capital inputs or even spur new technological innovations in ways that undermine the long-run applicability of models estimated before the change. However, the possibility that institutional selection effects can act upon the dominant short-run margins of fishing production presents the inconvenient possibility that traditional production estimates may be fragile or unsuitable for even the most circumscribed forms of ex ante policy evaluation.

We demonstrate this fragility through a stylized representation of an aggregate multispecies fishing production in the extreme short run, using the deployment of fishing time over space as the only variable margin of decision making. Using a combination of analytical and simulation techniques, we show how the properties commonly associated with aggregate production relationships can be synthesized from the deployment of a vessel's fishing time over a set of spatially distinct joint production technologies. We further demonstrate that when fishermen select locations to maximize utility subject to economic and institutional constraints, the shape and scale of the revealed (i.e., empirically identifiable) aggregate production relationship is highly dependent on the institutional setting under which production data is generated. Thus, the revealed aggregate production relationship is not policy invariant, and is limited in its ability to inform policy makers of the outcomes of fishery policy interventions a priori. Our findings suggest that accurate prediction of the impacts of a policy intervention requires a description of the fishing 
production process that is sufficiently structural so as to be invariant to changes in management institutions.

We illustrate these problems by focusing on the ability to substitute between species in a multispecies context, as reflected in the shape of the output transformation frontier. Species substitution is critical to many questions in fisheries management since it summarizes the extent to which fishermen can "target" a particular species. Targeting ability, in turn, determines the degree to which fishermen may be able to accommodate their catch to quota holdings in a multispecies ITQ system or respond to incentives to avoid bycatch. For example, previous studies using data prior to a policy intervention conclude that fishermen have limited targeting ability due to weak substitution potential between species (Squires 1987b; Squires and Kirkley 1991; Squires, Alauddin, and Kirkley 1994; Squires and Kirkley 1996; Pascoe, Koundouri, and Bjørndal 2007; Pascoe, Punt, and Dichmont 2010). In contrast, ex post evidence from multispecies ITQ fisheries reveals far greater flexibility in output substitution than previously thought (Sanchirico et al. 2006; Branch and Hilborn 2008; Abbott, Haynie, and Reimer 2015). An explanation for these disparate findings consistent with our analysis is that since the empirical ex ante production technology is jointly determined with institutions and incentives facing fishermen, it does not necessarily yield a policy invariant estimate of production possibilities. Substitution possibilities revealed under one set of incentives before a policy change may, therefore, not be informative about substitution possibilities under another set of incentives immediately after an institutional change.

\section{THE FISHERY PRODUCTION FUNCTION AND FISHERIES MANAGEMENT:} AN OVERVIEW

Natural resource economists and fisheries scientists have a long history of using aggregated and general production functions to depict the fishing production process. In its earliest form, fishery production was represented by an aggregate landings function, in which industry harvest $y$ was assumed to be a function of fishing effort $E$ and the biomass of a single stock of fish $X, y=$ $f(E, X)$, where effort was often interpreted as the number of boats in the fishery (Crutchfield and Zellner 1961; Clark 1973; Clark and Munro 1975). Models based upon this simple representation of fishery production provide powerful "metaphors" (Smith 2012) that form the bedrock of the theory of fisheries management, including canonical models of open access and sole ownership (Gordon 1954; Scott 1955). Nonetheless, literal interpretations of effort as the number of boats led to the popular interpretation of the rent dissipation process as one of "too many boats chasing too few fish;" limited entry was, therefore, the logical policy. However, the checkered record of limited-entry fisheries made it clear that there were many unregulated dimensions of effort that fishermen could continue to manipulate, leading to unanticipated dissipation of economic rents and challenges in managing fishing mortality (Pearse and Wilen 1979; Wilen 1979, 1988).

Economists responded to this evidence by extending models of fishery production to include more realistic aspects of fishing technology. Early extensions viewed effort as part of a multistage optimization process, whereby quasi-fixed factors of production $\mathbf{x}_{f}$ - such as vessel length, tonnage, engine size, gear type, and crew size - and variable factors of production $\mathbf{x}_{v}$ - such as aggregate measures of fishing time and fuel consumption - are efficiently combined to form an aggregate input index (effort) in the first stage, $E=E\left(\mathbf{x}_{f}, \mathbf{x}_{v}\right)$, and subsequently used as an input in the fishery production in the second stage $y=f\left(E\left(\mathbf{x}_{f}, \mathbf{x}_{v}\right), X\right)$ (Rothschild 1972; Anderson 1976; 
Cunningham and Whitmarsh 1980; Hannesson 1983). Squires (1987a) pointed out that the aggregate effort index can only be formed if it is possible to meaningfully rank alternative levels of effort without knowing the levels of species harvested (i.e., homothetic separability). ${ }^{1}$

While many, if not most, fisheries are characterized by the joint production of multiple species, this was largely ignored in early models of fishing production. The salience of joint production became clear to economists as many multispecies fisheries began implementing portfolios of total allowable catches (TACs) using collective or individual output quotas. Lack of output substitutability can lead to failure to balance individual TACs with the actual catch composition of the fleet, potentially resulting in rampant illegal discarding, data fouling, and overharvesting of the "choke" species (Copes 1986). Early models of fishing production either focused on a single species or combined multiple species into an aggregate index (output), effectively imposing input-output separability on the fishing production technology. ${ }^{2}$ Furthermore, management systems for multispecies fisheries typically set TACs for each species individually without consideration of potential biological or technical interactions between stocks. As recognized by Squires (1987a), this form of management effectively assumes that separate production processes exist for each species (i.e., production is nonjoint in inputs), thereby permitting each species to be separately regulated without affecting harvest of any other species.

Recognizing the limitations of imposing a priori input-output separability and nonjointness in inputs on the fishing production process, Squires (1987a,b) and Kirkley and Strand (1988) examined fishing technology indirectly using dual formulations (Shephard 1970; Diewert 1974; McFadden 1978), resulting in a significant body of literature. ${ }^{3}$ In recent years, flexible primal approaches to characterizing multispecies fisheries have also emerged, relaxing the need for behavioral assumptions, such as cost minimization or profit maximization, that may not hold in many regulated fisheries (Weninger and Waters 2003; Felthoven and Morrison Paul 2004; Pascoe, Koundouri, and Bjørndal 2007; Weninger 2008; Pascoe, Punt, and Dichmont 2010). In general, these studies have found that the plausibility of assuming input-output separability and nonjointness in inputs depends critically on the specific features of the examined fishery, especially in regards to fishing gear and the spatial and seasonal co-occurrence of the targeted species (Jensen 2002).

The advancement of multi-output production models has allowed economists to address management problems unique to multispecies fisheries, particularly those associated with "catchquota" balancing issues for fisheries managed by output quotas. An early and highly influential analysis of the effects of output controls on a multispecies fishery was conducted by Squires (1987b), who investigated the failed attempt to manage multiple species through output controls in the New England trawl fisheries. Squires found widespread complementarity among outputs, concluding that output controls failed because individual species quotas were not set in balance with natural output mixes and that fishermen were limited in their ability to substitute between

1. Squires (1987a) went on to provide a means to empirically test the structure of production for the existence of fishing effort and demonstrated the theoretically proper manner by which to construct a consistent effort index.

2. Separability between inputs and outputs allows the total catch of multiple species to be represented by a composite index. Input-output separability implies that the marginal rates of transformation between species pairs are independent of input choices. This implies that fishermen make their decisions on optimal species independent of their decisions on input combinations (Squires 1987a).

3. A dual formulation exploits assumptions regarding a firm's profit or revenue maximization or cost minimization behavior to enable an indirect examination of output substitution possibilities through the use of a flexible, single-valued profit, revenue, or cost function. 
species. This work was succeeded by a number of ex ante evaluations gauging the likelihood of success for output controls in multispecies fisheries. Many have conveyed a similar message: output controls for multispecies fisheries may be in jeopardy due to weak substitution potential between species (Squires and Kirkley 1991, 1995, 1996; Pascoe, Koundouri, and Bjørndal 2007; Pascoe, Punt, and Dichmont 2010).

Contrary to the warnings conveyed by ex-ante evaluations, recent evidence from multispecies fisheries with output controls - particularly those with individual or cooperative harvesting rights - have found that fishermen are often far more capable of adjusting their output composition than previously thought (Sanchirico et al. 2006; Branch and Hilborn 2008; Abbott, Haynie, and Reimer 2015). These disparate findings suggest that current empirical fisheries production models may provide misleading inferences about the substitution potential of fishing technology. We argue that this occurs because these models ignore one of the most fundamental ingredients for adjusting output composition: the decision of where and when to fish, which may be highly institution dependent. ${ }^{4}$

In hindsight, it is perhaps understandable that conventional representations of the fishery production process may be deficient for policy analysis. For the most part, fisheries economists have adapted conceptual and econometric structures originally developed to analyze more traditional production processes, most notably agriculture. But fisheries are unlike agriculture in fundamental ways. Most importantly, in fisheries, the "plant" is brought to the input (fish stock) rather than vice versa. The dominant short-run decisions thus involve repeatedly deciding where and when to locate over space across time, whereas similar spatial decisions are far more likely to be (quasi) fixed in the short-run for more conventional industries such as agriculture. Production function estimates that regress temporally aggregated landings on measures of cumulative input use thus obscure the most important micro-decisions that consume fishermen's continuous attention, namely how to use space and time in pursuit of the resource.

Historically, the spatiotemporal dimension of fishery production was largely ignored due to a lack of understanding of spatial fishing behavior. In recent years, economists have begun to recognize the importance of incorporating space, time, and information into behavioral models of harvesters, resulting in a flourishing body of literature on spatial choice of fishing locations (Eales and Wilen 1986; Curtis and Hicks 2000; Holland and Sutinen 2000; Smith and Wilen 2003; Haynie, Hicks, and Schnier 2009; Abbott and Wilen 2011). The analysis of spatial choice of fishing locations addresses short-term aspects of the fishing production process and assumes that production decisions, such as capital investment, have already been made. In general, empirical studies of spatial behavior find evidence that fishermen often behave according to economic theory - being more likely to choose locations with high-expected revenues, short travel distances, and low risk.

Evidence emerging from studies of spatial fishing behavior suggests that understanding the spatiotemporal behavior of fishermen - and the influence of market conditions and management institutions on this behavior-is an important, albeit neglected, input margin to consider in models of fishery production. The mixture of species available to a fishery gear often varies substantially over space and time, driven by inter-species differences in habitat preferences, for-

4. A notable exception is the "sample-selection" production model estimated by Campbell (1991), where area-specific production functions are estimated and corrected for potential selection bias by incorporating results from an auxiliary probit model of fishing area choice. 
aging and spawning behavior, and response to fluctuations in the marine environment. Therefore, very different output bundles are possible for a given amount of measured aggregate inputs (i.e., fishing hours), depending on how this effort is allocated in space and time. Most important to our argument, recent work on location choices indicates that the institutional setting of a fishery influences spatial fishing behavior (Haynie, Hicks, and Schnier 2009; Abbott and Wilen 2010; Abbott and Haynie 2012; Abbott, Haynie, and Reimer 2015). As a result, the output production possibilities revealed by data generated under a single institutional regime may provide a partial or misleading picture of the complete production technology, raising a number of important questions for modeling aggregate fishery production. How does the spatial dimension of fishing influence aggregate production relationships? How do institution-dependent decisions of where and when to fish shape the production technology revealed by fishery-dependent data? What are the implications of ignoring the institutional dependence of spatial choices for ex ante policy prediction?

\section{FISHING PRODUCTION TECHNOLOGY: A SIMPLE BASELINE MODEL}

Our investigation begins with a simple model of fishing production that borrows from the work of Jones (2005), which addresses the micro-foundations of the aggregate production function in economic growth models. In his model, firms draw from a stock of ideas - a collection of local production functions - showing different ways to combine labor and capital to produce an output. These local production functions differ in their underlying labor and capital-augmenting parameters. He then shows how the shape of the overall global production function of the economy, when the set of all local production techniques are available, is entirely driven by the "menu" of local production functions, rather than the properties of the local production functions themselves. ${ }^{5}$ The fundamental insight is that the properties of the aggregate production function are emergent properties of the heterogeneity in underlying production techniques. Understanding this heterogeneity is a critical element in knowing the properties of the aggregate production technology. ${ }^{6}$

As a simple illustration of this larger point to the fisheries context, we adapt the theory of Jones (2005) to consider the case of a stock-flow production process whereby fishermen apply fishing technology (e.g., a fishing vessel and gear) to spatially heterogeneous stocks of fish species to yield a flow of multiproduct catch or output. For simplicity, we consider a short-run production process in which fishing technology is fixed, so that only a single variable input $x$, time spent fishing, is applied to fish stocks to produce two outputs $y_{1}$ and $y_{2}$, the catch of species one and two, respectively (cf., Turner 1997). The global multispecies production technology is typically defined by the production possibilities set:

$$
P(x)=\left\{\left(y_{1}, y_{2}\right): T\left(x, y_{1}, y_{2}\right) \leq 0 ;\left(y_{1}, y_{2}\right) \geq \mathbf{0}\right\}
$$

5. More specifically, he shows that a "menu" of production parameters for local Cobb-Douglas production functions will yield a global production function in Cobb-Douglas form as well. He also shows that a global Cobb-Douglas production can be produced regardless of the underlying local production functions, under the condition that the local production techniques are selected randomly from an underlying Pareto distribution.

6. As noted by Jones (2005), putty-clay models of production (e.g., Johansen 1959; Hu 1972) make a similar distinction between ex ante and ex post technology, with respect to capital-labor elasticities before and after capital investment, as opposed to the local-global distinction made here. 
where non-positive values of $T\left(x, y_{1}, y_{2}\right)$ define the quantities of $y_{1}$ and $y_{2}$ that can be feasibly produced from a given amount of input $x .^{7}$ When $T\left(x, y_{1}, y_{2}\right)=0$, production is technically efficient in the sense that additional output of both $y_{1}$ and $y_{2}$ cannot be produced for the value of $x$. The implicit function given by this equality defines the transformation frontier between inputs and outputs. If we fix $x$ and then examine the values of $y_{1}$ and $y_{2}$ that lie along the transformation frontier, this defines the output transformation frontier - the production possibilities between the two species.

In most applications, the production technology in (1) is imposed upon fishing vessels without much consideration of its micro-foundations. How does this relationship spring from the "on the water" decisions of fishermen, and what determines its shape? Furthermore, the existence of substitution possibilities between outputs along the global output transformation frontiereven after all modeled inputs are fixed - begs the question of exactly what underlying margin or un-modeled input is manipulated to accomplish this substitution. How can the output mix between species be changed without altering the quantity of fishing time? At the basis of all conventional multi-output production modeling lies an undefined mechanism for redirecting the committed inputs to produce any feasible output bundle that lies within the production set. ${ }^{8}$

In Jones (2005), this mechanism lies in the ability to allocate inputs, either in whole or part, over a menu of local production functions. In our context, this mechanism occurs as fishermen distribute fishing time $x$ across different fishing locations to exploit a heterogeneously distributed fish stock. Suppose that there exists a Schaefer (1954) production technique at each possible fishing location $j$, represented by the two-dimensional production function $\left(y_{1}, y_{2}\right)=\left(a\left(\mathbf{z}_{j}\right)\right.$, $\left.b\left(\mathbf{z}_{j}\right)\right) x v$, where $0 \leq v \leq 1$ is a neutral form of technical efficiency and $\mathbf{z}_{j}$ is a vector of locationspecific state variables, such as local biomass of both species and the state of the local environment and habitat. The parameters $a\left(\mathbf{z}_{j}\right)$ and $b\left(\mathbf{z}_{j}\right)$ can, therefore, be interpreted as the catch per unit effort (CPUE) for species one and two, respectively, conditional on state variables $\mathbf{z}_{j}$ at location $j$. A Schaefer production technology at each location $j$ gives rise to the following local production possibilities set:

$$
P_{j}\left(x, \mathbf{z}_{j}\right)=\left\{\left(y_{1}, y_{2}\right): y_{2}=\frac{b\left(\mathbf{z}_{j}\right)}{a\left(\mathbf{z}_{j}\right)} y_{1} ; 0 \leq y_{1} \leq a\left(\mathbf{z}_{j}\right) x\right\},
$$

which can be depicted by a ray from the origin in output space (figure 1). ${ }^{9}$ For simplicity, and for congruence with the short-run focus of the subsequent analysis, we consider only short-run production over a time interval in which local state variables are constant at level $\check{\mathbf{z}}_{j}$, and thus, local

7. See McFadden (1978) for the conditions on technology required to express the production set using the transformation function $T$.

8. Frisch (1964) believed that such questions could be addressed by modeling technology using more than one implicit functional relation between inputs and outputs. In particular, he suggested using $\mu$ independent transformation functions to more precisely describe the mechanisms by which an assortment of outputs can be produced using a given quantity of inputs: $P(x)=$ $\left\{\left(y_{1}, y_{2}\right): T^{1}\left(x, y_{1}, y_{2}\right) \leq 0, \ldots, T^{\mu}\left(x, y_{1}, y_{2}\right)\right\}$. Frisch defined the relation between the number of outputs $(M)$ and transformation functions as the degree of assortment: $\alpha=M-\mu$.

9. Formally, the technology in equation (2) displays weak output disposability, which holds if $\left(y_{1}, y_{2}\right) \in P(x)$ and $\theta \in[0,1]$, then $\left(\theta y_{1}, \theta y_{2}\right) \in P(x)$, meaning that a reduction in either output is always feasible as long as both outputs are reduced proportionally. One way to justify weak output disposability is to redefine fishing time as "time on grounds $j$," where this time can be allocated to fishing, in proportion $\theta$, and non-fishing time. This assumption guarantees convex global production sets in the subsequent analysis but is not necessary for proving our larger argument. Since we model catch rather than landed catch (where discards separate the two), the more common assumption of free disposability is not justified here. 


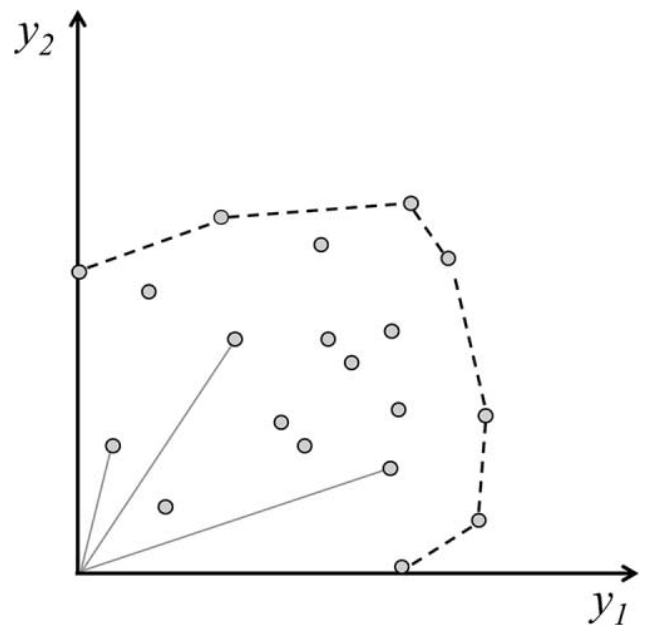

Figure 1. An Example of a Global Production Set

Note: Each grey dot represents the technically efficient production vector corresponding to a particular location. For some of these locations, their associated loca/ production set has been drawn as a grey ray from the origin. The area encompassed by the black dashed line represents the global production set, which is the convex hull of the local production sets.

production techniques are determined solely by the parameters $a\left(\check{\mathbf{z}}_{j}\right)$ and $b\left(\check{\mathbf{z}}_{j}\right)$, henceforth referred to as $a_{j}$ and $b_{j}{ }^{10}$ The technology implied by equation (2) reflects the fact that the combined catch $\left(y_{1}, y_{2}\right)$ always occurs in the fixed proportion $b_{j} / a_{j}$, indicating a complete lack of substitution potential between species at any location $j$. If a firm wants a catch composition ratio that differs from $b_{j} / a_{j}$, another location with a different local production set must be selected.

The set of local production techniques across locations serves as a basis for a global production set - which shows the set of all possible production bundles that can be produced using the entire set of fishing locations that are available. As recognized by Jones (2005), this global production set does not represent a single technology; rather, it is a reduced-form representation capturing the substitution possibilities across different local production techniques. In general, it is the distribution of local production parameters, rather than the properties of individual local production technologies, that drive the shape and curvature of the global production frontier. In our context, this means that the elasticity of substitution between species for the global technology depends on the relative distribution of species across locations.

To illustrate this more formally, consider the simple case where the single input fishing time can only be allocated to a single fishing location. Imagine that there is a continuum of potential fishing locations such that the combination of CPUE parameters $a$ and $b$ available to fishermen through their spatial choices are represented by the constant elasticity of substitution (CES) technology "menu":

10. In the long-run, we would expect the $\left(a_{j}, b_{j}\right)$ parameters to change in response to growing and/or moving stocks and changing environmental conditions. Such changes, however, are not changes in the local production technologies per se, but are instead changes in underlying states $\mathbf{z}_{j}$ accounted for in the local production technology. We therefore view the $\left(a_{j}, b_{j}\right)$ parameters as "reduced-form" parameters for a description of the technology that treats these states as fixed. Importantly, fishermen only perceive the $\left(a_{j}, b_{j}\right)$ parameters without ever knowing the 'true' state of the underlying states or their functional relationship to the reduced-form parameters. 


$$
H(a, b)=\left(\beta a^{r}+(1-\beta) b^{r}\right)^{\frac{1}{r}}=N,
$$

where $r \geq 1$ and $a, b, \beta, N \geq 0$. The role of $N$ is to shift the menu out in $(a, b)$ space, permitting higher CPUEs of both species. Any combination of $a$ and $b$ along this technology menu is associated with a local production set in the form of equation (2). The global production set encompasses all possible combinations of $y_{1}$ and $y_{2}$ for a given amount of input $x$, when the firm is able to choose any single combination of $(a, b)$ according to the technology menu in equation (3). Technically efficient production requires $\left(y_{1}, y_{2}\right)=(a, b) x$, implying that $a=y_{1} / x$ and $b=y_{2} / x$ at any given location. Thus, using these expressions to substitute in the technology menu $H(a, b)$ for $a$ and $b$, the frontier of the global production frontier is easily shown to be the CES function:

$$
T\left(x, y_{1}, y_{2}\right)=\left(\beta y_{1}^{r}+(1-\beta) y_{2}^{r}\right)^{\frac{1}{r}}-x N=0 .
$$

Thus, in this case, the shape of the global production frontier, and its elasticity of substitution $1 /(1-r)$, depends entirely on the parameters that shape the technology menu for the locationspecific parameters.

A continuum of fishing locations, as implied by the technology menu in equation (3), is required for a continuous global transformation function under the assumption that fishing time $x$ can only be allocated to a single fishing location. However, it is possible for the global production frontier to be continuous even with a discrete and finite number of fishing locations, as long as fishing time is continuously divisible across fishing locations. ${ }^{11}$ To see this, consider a scenario in which fishing time $x$ can be continuously divided over a square grid of discrete fishing locations, where the CPUE parameters $a$ and $b$ vary over the grid. ${ }^{12}$ Figure 2 displays six different distribution scenarios for the CPUE parameters $a$ (column one) and $b$ (column two). Each location in the grid is associated with its own (not necessarily unique) local production set in the form of equation (2). The technically efficient production bundle $\left(y_{1}, y_{2}\right)$ for each location is mapped into output space for each of the six different distribution scenarios, as depicted by the scatter points in column three of figure 2 . Since fishing time is continuously divisible over locations, the global production set includes all convex combinations of production possibilities - including inefficient production bundles along the ray to the origin - and thus, the global production set is the convex hull of all local production technologies. ${ }^{13}$

It is clear from figure 2 that the joint distribution of species abundance can drastically alter the shape of the global output transformation frontier - exhibiting the full spectrum of relationships between strong substitutability and complementarity, as well as combinations of both at different points on the output transformation frontier. The top two rows in figure 2 depict spatial distributions of species with relatively little overlap, resulting in a production set in which

\footnotetext{
11. See Shumway, Pope, and Nash (1984) for a discussion on the jointness implications for modeling production when allocatable inputs are fixed (such as fishing time here).

12. CPUE parameters $a$ and $b$ vary over the grid according to two-dimensional normal density functions, each with their own mean and variance. Details can be found in the online-only appendix.

13. Our method for identifying the global production set as the convex set hull of all local production techniques bears some resemblance to a pseudo-data modeling approach, whereby engineering process models and linear programming are combined to generate aggregate production pseudo data, upon which econometric tools are applied to estimate the aggregate (or industry-wide) production frontier (e.g., Griffin 1978; Smith and Vaughan 1979).
} 
Species 1
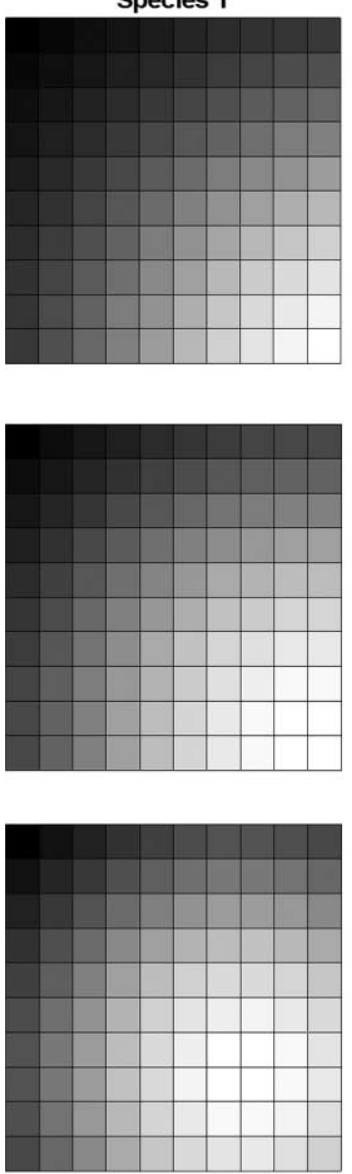

Species 2
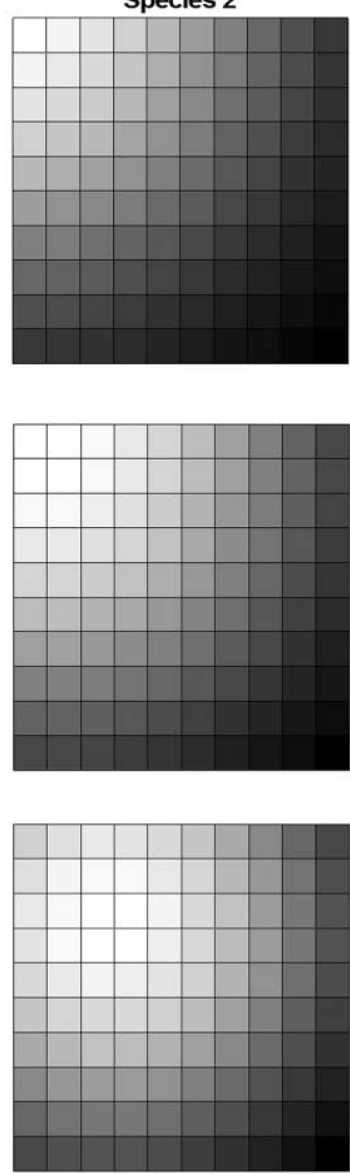

Production Possibilities Set
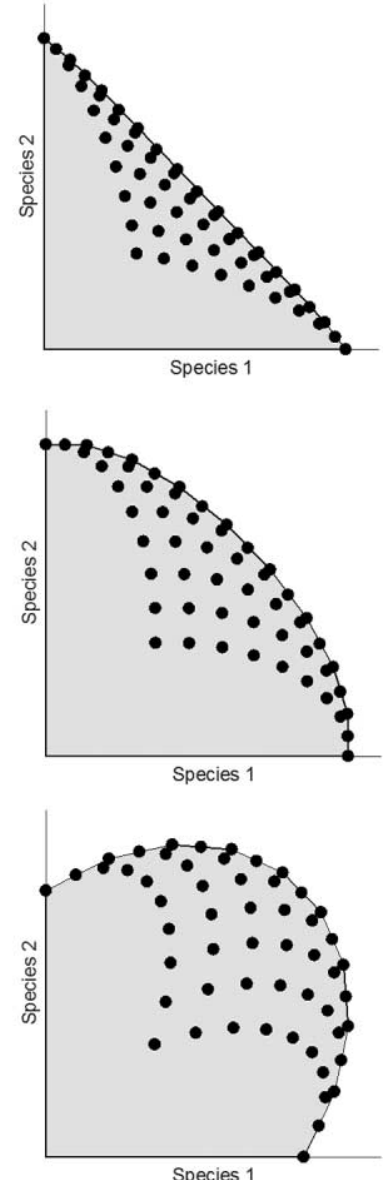

Figure 2. Global Production Sets-Spatial Distribution of CPUE Parameters for Species One (Left Column) and Species Two (Middle Column) and the Resulting Global Production Set (Right Column) for Six Biological Scenarios (Rows)

Note: Dark-shaded areas correspond to areas with low CPUE, while light-shaded areas correspond to areas with high CPUE. The black dots within the production sets correspond to the unique technically efficient local production vectors, and the black curve represents the global transformation frontier.

the outputs are uniformly substitutes-in-production - i.e., catching more of one species requires catching less of the other. In both scenarios, a firm can adjust the composition of their outputs with relative ease (particularly in row one), in the sense that the opportunity cost of trading one output for another is fairly constant along the entire frontier. Moreover, a firm can "costlessly" target a single species in the sense that avoiding the catch of one species does not come at the cost of reducing the catch of the other. This characteristic of production technology is associated with free disposability, or "perfect control of harvest composition" (Turner 1997).

As the spatial distributions of the species exhibit a greater degree of overlap (e.g., rows three and four), the global production set progressively bows outward, indicating increased possibilities for the joint production of species one and two. However, these additional joint output 
Species 1
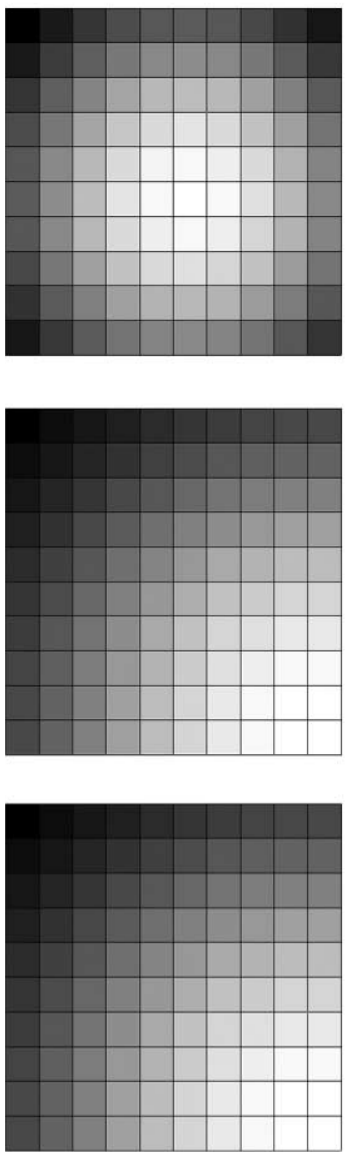

Species 2
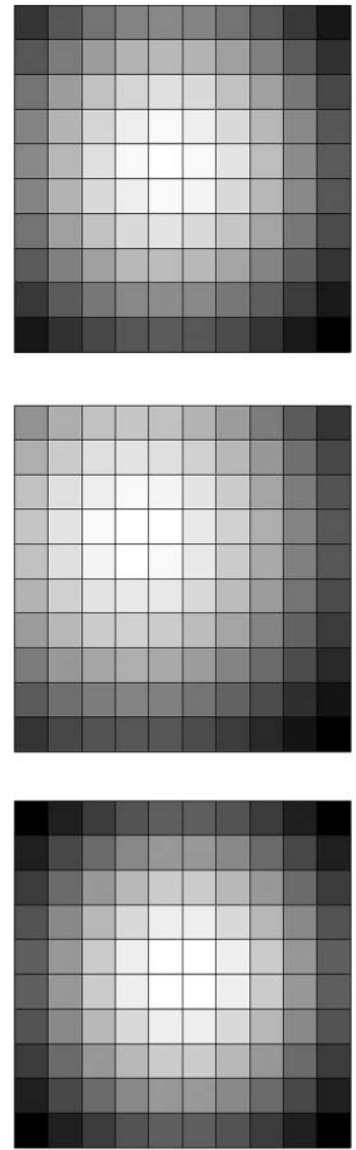

Production Possibilities Set
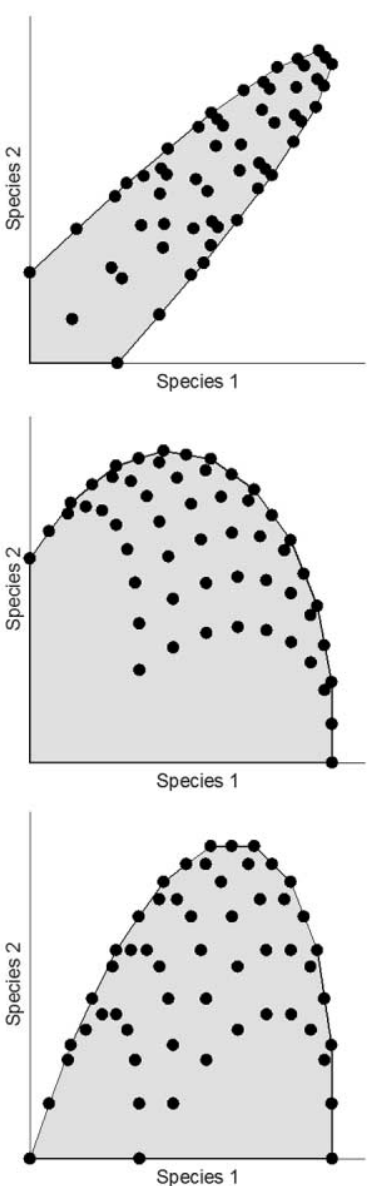

Figure 2 (Continued)

possibilities come at the cost of reduced targeting capabilities. Indeed, for small catch levels for either species, the outputs are complements-in-production-i.e., catching less of one species requires catching less of the other. ${ }^{14}$ This characteristic of production technology is typically associated with weak output disposability-or "imperfect control over species composition" (Turner 1997). ${ }^{15}$

The global production frontier can also exhibit characteristics of both substitutability and complementarity over different ranges of the frontier if the relative spatial distribution of the two species is asymmetric, as in rows five and six. For these two scenarios, species two is widely distributed across locations, while species one is contained to a specific area of the grid, result-

14. This is particularly true for the scenario depicted in row four, in which the two spatial distributions almost perfectly overlap. In fact, if spatial distributions of species one and two perfectly overlap, the global production set is equivalent to a ray from the origin, indicating perfect complements.

15. See footnote 9 . 
ing in a global production frontier in which species one can be perfectly targeted but species two cannot. In fact, it is not possible to catch species two without catching species one for the scenario depicted in row six. This characteristic of production technology is known as "nulljointness" - an assumption commonly used to model technology with undesired byproducts, such as pollution (Färe et al. 2005), but only arises here as a special case.

\section{IDENTIFYING THE AGGREGATE PRODUCTION FUNCTION FROM FISHERY-DEPENDENT DATA}

Our investigation thus far demonstrates how the output substitution possibilities in a fishery can be constructed, in theory, from the structural microfoundations of where to fish. Of course, an important question still remains: how does an analyst identify the global production technology empirically? In an ideal world, we would estimate the global frontier implied by equation (4) using a comprehensive sample of fishing locations that produce catch compositions along the entire global production frontier. Unfortunately, we rarely have such a dataset; instead, common practice is to estimate aggregate production functions using data generated by the real-world location decisions of fishermen. The following questions then emerge: can data generated by realworld location decisions of fishermen identify the global production technology? If not, what are we estimating when we use such data to characterize fishing production technology?

To investigate these questions, we construct a fishing production dataset generated from simulated location-choice decisions made by utility-maximizing fishermen. We then compare the aggregate production frontier that is revealed by our simulated dataset to the global production frontier depicted in figure 2, clearly demonstrating that the two production frontiers are not equivalent.

\section{LOCATION CHOICE MODEL}

As in the baseline model, firms are assumed to adjust their catch of species one $y_{1}$ and two $y_{2}$ by allocating fishing time $x$ across a square grid of fixed-proportions local production techniques. To focus on the role of spatial selection, we assume stationary local distributions of the resource over our short-run production horizon. ${ }^{16}$ How a firm actually allocates fishing time across locations depends on the cost of traveling between locations and the relative prices of the two species. To allow firms to divide fishing time $x$ across multiple locations, we assume that firms choose a single fishing location in each of $T$ fishing periods of unit length, so that fishing time is constant over all observations and equal to $T \cdot{ }^{17}$ Specifically, in each time period $t=1, \ldots, T$, a fisherman chooses from a discrete set of $J$ locations to fish so that the proportion of total fishing time allocated to location $j$ is equal to $T^{-1} \Sigma_{t=1}^{T} I_{t j}$, where $I_{t j}$ equals one if a fisherman fished at location $j$ at time $t$, and zero otherwise. The catch of each species is, therefore, the sum over all catches made over the $T$ periods: $y_{s}=\sum_{t=1}^{T} \Sigma_{j=1}^{J} I_{t j} y_{t j s}$ for $s=1,2$, where $y_{t j s}$ is the catch of species $s$ at location $j$ at time $t$.

Consistent with much of the empirical literature (e.g., Eales and Wilen 1986; Curtis and Hicks 2000; Holland and Sutinen 2000; Mistiaen and Strand 2000; Smith et al. 2010), we assume

16. While admittedly a stylized assumption, our model bears some resemblance to demersal trawl fisheries, which constitute some of the world's largest fisheries.

17. For instance, a production observation could be interpreted as a trip, so that fishing time $x$ is total time spent fishing during a trip, with $T$ being the length of fishing time during a trip. 
fishermen select a fishing location at time $t$ to maximize their contemporaneous utility. ${ }^{18}$ We model fisherman i's utility to be the sum of a deterministic and stochastic component:

$$
U_{t j}=v_{t j}+\varepsilon_{t j}
$$

where we have omitted the individual-specific subscript $i$ for expositional clarity. We assume that the stochastic components $\varepsilon_{t j}$ enter into fishermen's decision utility prior to selecting a location, are independent and identically distributed Type 1 Extreme Value, and can be interpreted as an "optimization error" that arises from not knowing the distribution of CPUE parameters over space with certainty. The deterministic portion of utility is modeled as:

$$
v_{t j}=p_{1} a_{j}+p_{2} b_{j}-\beta d_{t-1, j}
$$

where $p_{s}$ is the price of catch for species $s, a_{j}$ and $b_{j}$ are the CPUE parameters for species one and two at location $j$, and $d_{t-1, j}$ is the distance between location $j$ and the fisherman's previous location choice in period $t-1$, with $\beta$ representing the marginal cost of travel, which is the same for all fishermen.

The catch of each species at a given location and time is modeled to be consistent with the fixed-proportions technology in equation (2):

$$
y_{t j 1}=a_{j} e^{-u_{t}} \text { and } y_{t j 2}=b_{j} e^{-u_{t}} .
$$

The term $0<e^{-u_{t}} \leq 1$ represents a firm's technical efficiency, where $u_{t}$ is assumed to have a onesided (non-negative) exponential distribution, which is consistent with the empirical production literature (Coelli et al. 2005). The local production technique at a given location can, therefore, be depicted as a ray from the origin in production space, as in figure 1. The CPUE parameters $a$ and $b$ are assumed to remain constant over all individuals and $T$ time periods, resulting in global production frontiers that are identical to those depicted in figure 2. In contrast, the inefficiency shocks $u_{t}$ are individual- and time-specific. ${ }^{19}$

\section{ECONOMIC AND INSTITUTIONAL TREATMENTS}

We generate simulated data of location choice sequences and production outputs under different "treatments" to show that fishermen effectively sample from very different regions of the global output production set, depending on the institutional and economic setting of a fishery. Changes in the economic and institutional setting are reflected in the model through changes in the cost of travel $\beta$ between fishing locations and variations in the relative prices of the two outputs $p=\left[p_{1}, p_{2}\right]$. Changes in $\beta$ can be viewed as a change in the technological cost of travel, due to an increased fuel price for instance, or as a change in the institutional-dependent opportu-

18. A more complete model of fishing behavior would incorporate dynamic choices over fishing trajectories (e.g., Hicks and Schnier 2006, 2008). However, doing so adds considerable computational complexity and tends to reduce the spatial dispersal in location choices without fundamentally altering our qualitative findings.

19. It is fairly standard in the literature to model the deterministic portion of utility to be a function of location-specific expected catch or revenues. By modeling indirect utility as a function of the technically efficient CPUE parameters $a_{j}$ and $b_{j}$, we are implicitly assuming that the expected catches at location $j$ are made assuming that expected technical efficiency is equal to one. Note that this assumption does not affect our simulation results since $u_{t}$ is assumed to be location- and species-invariant, and does not therefore change the relative attractiveness of a location. Thus, inefficiency shocks do not affect the location decisions of fishermen. In general, the overall message of our simulation exercise does not depend on the form of expectations used in the location choice model, as long as fishermen are modeled to act purposefully with respect to the underlying spatial distribution of CPUE, as opposed to randomly. 
nity cost of travel. For example, under "race-to-fish" institutions, an additional opportunity cost arises due to the time spent not fishing as other fishermen race to maximize their catch under the rule of capture (Abbott and Wilen 2011; Reimer, Abbott, and Wilen 2014). Similarly, changes in the relative output prices can be viewed as changes in the relative shadow prices between two species that may arise, for instance, from the transition from a system of insecure harvest rights to a system of harvest quotas. ${ }^{20}$

\section{SIMULATION RESULTS}

To focus our results, we generate four simulated datasets for a single biological scenario (row three of figure 2) for all combinations of two different relative output prices $(p=[-1,1], p=$ $[2,1])$ and two different travel costs $(\beta=0$ and $\beta=4) .{ }^{21}$ For simplicity, fishermen are assumed to start each trip from "port" in the southwest corner of the grid (cell $[1,1])$. All stochastic utility components $\varepsilon_{t j}\left(\mathrm{E}\left(\varepsilon_{t j}\right) \approx 0.577 ; \operatorname{Var}\left(\varepsilon_{t j}\right)=\pi^{2} / 6\right)$ and inefficiency shocks $u_{t j}\left(\mathrm{E}\left(u_{t j}\right)=0.25\right.$; $\left.\operatorname{Var}\left(u_{t j}\right)=0.125\right)$ are identical across simulations so that the only difference between data generating processes is the parameters representing the "treatment"-i.e., the economic and institutional setting of the fishery. Each dataset contains observations from 1,000 fishermen, with each fisherman making a location choice in each of $T=3$ periods, for a total of 3,000 location choices and 1,000 "seasonal" aggregate production observations.

The results from our simulation exercise show that fishermen select different location sequences across treatments depending on the economic and institutional setting-effectively sampling from very different regions of the global output production set. The heat maps in figure 3 illustrate the density of location choices across the grid, while the scatter plots display the resulting output bundles from the simulated location sequences. For ease of comparison, the simulated output bundles overlay the global production set from figure 2. The output transformation frontiers revealed by our simulated data are depicted by black dashed lines, which act as the convex hull for the simulated output bundles. ${ }^{22}$

For the scenario $p=[2,1]$, fishermen place a positive value on the catch of both species with a relatively higher value for species one, resulting in location choices concentrated on areas of the grid with relatively high CPUE for species one. When there is no cost of travel $(\beta=0)$, fishermen concentrate their effort on locations near the peak of the CPUE distribution for species one (figure 2), effectively sampling from the southeast portion of the global production set. When fishermen incur travel costs $(\beta=4)$, fishing effort shifts closer to port and away from the peak of the CPUE distribution for species one, effectively shifting the sample of output bun-

20. An alternative way to generate institutional "treatments" is to simulate fishing effort as a profit-maximization problem with different institutional constraints, holding everything else constant (e.g., Reimer, Abbott, and Wilen 2014). In this sense, one can interpret the parameters $\beta$ and $p$ in our model as a combination of market prices and the shadow values that emerge from binding institutional constraints. Since the objective of our simulation exercise does not depend on separately manipulating economic and institutional parameters, we follow the more pragmatic approach of manipulating parameters that represent both the economic and institutional context of the fishery.

21. The overall message of our simulation exercise - i.e., the institutional dependence of the aggregate production function-is consistent across all biological scenarios. Results for the six scenarios depicted in figure 2, in addition to MATLAB code, is available upon request.

22. For illustration purposes, we depict the global and revealed production sets as being convex with continuous frontiers, even though the production sets from our simulation exercise will not be convex, simply because time is not continuously divisible across all locations when there is a finite number of time periods. We include multiple time periods so as to approximate a convex production set-and thus a continuous frontier-where the approximation improves as the number of time periods approaches infinity. We thank an anonymous reviewer for pointing this out. 

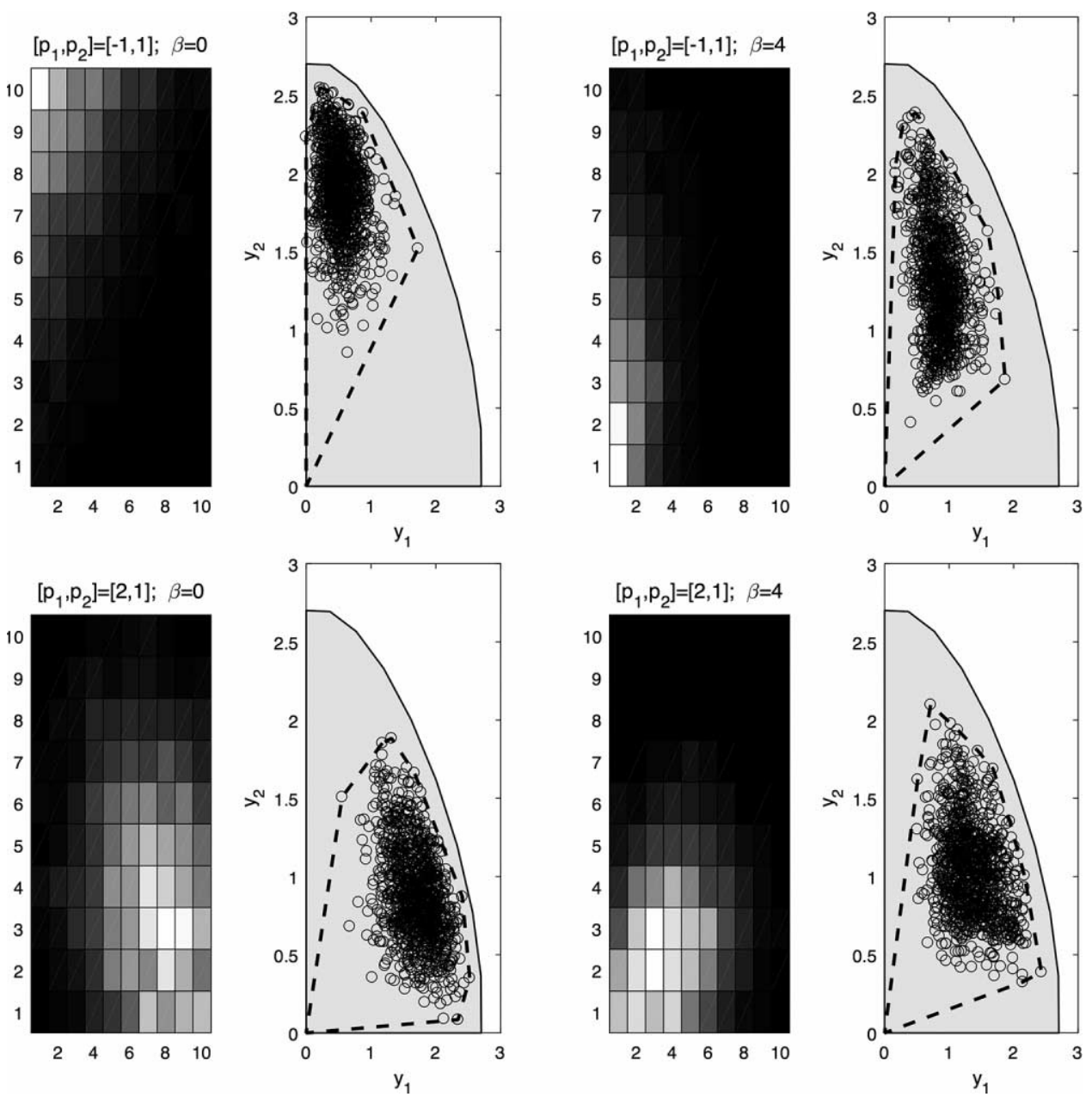

Figure 3. Empirically Revealed Production Sets-Density of Location Choices over the Grid (Heat Maps) and the Resulting Aggregate Production Bundles (Black Scatter Points) within the Global Production Set (Shaded Area)

Note: The revealed output transformation frontier generated by the simulated data (the convex hull) is depicted by the black dashed line. Stochastic variable assumptions: $\operatorname{Var}\left(\varepsilon_{t j}\right)=\pi^{2} / 6, \mathrm{E}\left(u_{t j}\right)=0.25, \operatorname{Var}\left(u_{t j}\right)=0.125$.

dles towards the center of the global production set. In both cases, the relatively low value of species two results in negligible fishing effort in the northwest portion of the grid, leading to an unsampled northwest portion of the global production set.

For the scenario $p=[-1,1]$, catch of species one is undesired, perhaps due to regulations that prohibit its retention or its existence as a choke species due to a binding output quota. When there is no cost of travel $(\beta=0)$, fishermen concentrate their effort on locations in the northwest corner of the grid where CPUE is at its highest for species two and lowest for species one, effectively sampling from the northwest portion of the global production set. When fishermen incur travel costs $(\beta=4)$, fishing effort shifts closer to port and away from the northwest corner of the grid, effectively shifting the sample of output bundles more towards the center of 
the global production set. In both cases, the negative value of species one results in negligible fishing effort in the southeast portion of the grid, leading to an unsampled southeast portion of the global production set.

The end result in all scenarios is a revealed transformation frontier that differs considerably, both in shape and scale, from the global transformation frontier. Indeed, with low travel costs, the revealed transformation frontier suggests that one species can be perfectly targeted while the other cannot - revealing a technology that is characterized by both complements-in-production and substitutes-in-production along different sections of the frontier. In contrast, the global transformation frontier is clearly characterized by substitutes-in-production along the entire frontier. The transformation frontier revealed by utility-maximizing fishermen is, therefore, a biased representation of the true global frontier in a manner reflecting the economic and institutional settings under which output data is generated.
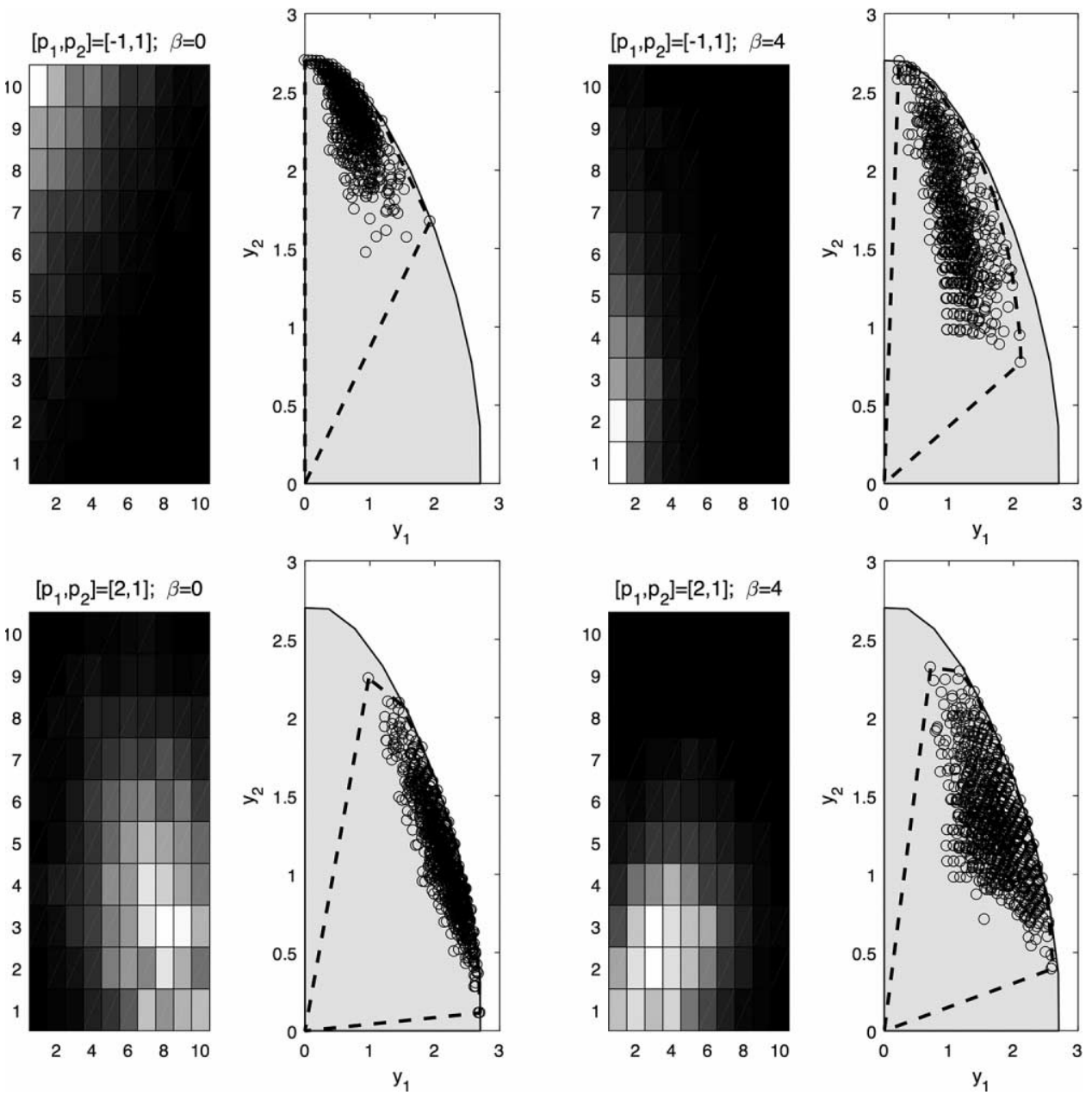

Figure 4. Empirically Revealed Production Sets with Targeting Ability and No Technical Inefficiency Note: Stochastic variable assumptions: $\operatorname{Var}\left(\varepsilon_{t j}\right)=\pi^{2} / 6, \mathrm{E}\left(u_{t j}\right)=\operatorname{Var}\left(u_{t j}\right)=0$. 
The extent to which the revealed transformation frontier differs from the global frontier depends on how capable fishermen are of consistently targeting their desired catch compositions and the degree of inefficiency fishermen experience at the local production level. For instance, suppose that fishermen are still relatively capable of targeting but no longer experience any technical inefficiency $\left(\mathrm{E}\left(u_{t j}\right)=\operatorname{Var}\left(u_{t j}\right)=0\right)$. The density of location choices is unchanged from figure 3 , but the resulting output bundles are scaled up towards the global transformation frontier (figure 4). In this case, the revealed production frontier resembles the global frontier in certain areas, but not in its entirety. The revealed production frontier, therefore, provides good "local knowledge" of the global frontier for the prevailing economic and institutional setting, but does not unveil the set of all possible production outputs that might be sampled under other environments. Now consider the case in which fishermen are less capable of targeting their catch. In our simulation model, targeting capability can be reduced by increasing the variance of the stochastic component of utility $\varepsilon_{t j}\left(\operatorname{Var}\left(\varepsilon_{t j}\right)=100 \pi^{2} / 6\right)$, which increases the "optimiza-
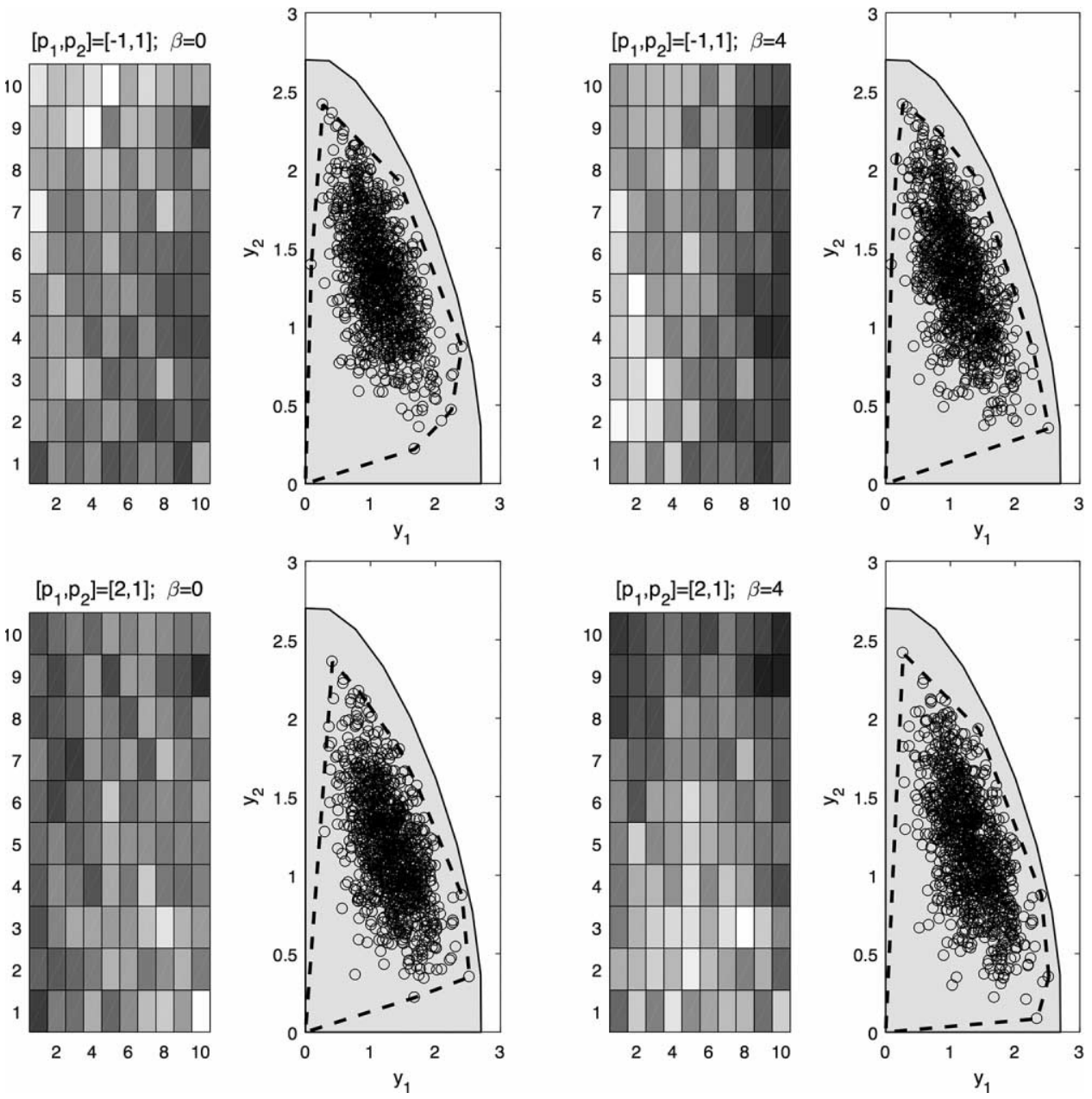

Figure 5. Empirically Revealed Production Sets with Reduced Targeting Ability and Technical Inefficiency Note: Stochastic variable assumptions: $\operatorname{Var}\left(\varepsilon_{t j}\right)=100 \pi^{2} / 6, \mathrm{E}\left(u_{t j}\right)=0.25, \operatorname{Var}\left(u_{t j}\right)=0.125$. 



Figure 6. Empirically Revealed Production Sets with Reduced Targeting Ability and No Technical Inefficiency Note: Stochastic variable assumptions: $\operatorname{Var}\left(\varepsilon_{t j}\right)=100 \pi^{2} / 6, \mathrm{E}\left(u_{t j}\right)=\operatorname{Var}\left(u_{t j}\right)=0$.

tion error" that arises from not knowing the distribution of CPUE parameters with certainty. ${ }^{23}$ The resulting density of location choices and output bundles span greater portions of the spatial grid and global production sets, respectively, resulting in a revealed transformation frontier whose shape more closely mimics that of the global transformation frontier in its entirety (figure 5). Eliminating technical inefficiencies in local production has the effect of scaling the revealed output bundles to the global transformation frontier (figure 6). The combined result is a revealed transformation frontier that closely resembles the global transformation frontier, as we would expect from a sample of location choices that is essentially random. These findings are anything but comforting. They suggest that the use of fishery-dependent data to draw infer-

23. Alternatively, and more consistently with the RUM formulation of discrete choice models in econometrics, increasing the variance of $\varepsilon_{t j}$ is equivalent to increasing the role of "unobserved heterogeneity" in fishermen's decision making —so that apparent observation error may simply be the result of optimization over a wider set of variables than is observed by the modeler. 
ences about production technologies will only be successful under unpalatable circumstances, namely where fishermen act quixotically, with their behavior minimally influenced by market and institutional parameters.

\section{DISCUSSION}

Fisheries economists are often tasked with predicting the effects of significant changes in management institutions. For the most part, economists' predictions about the implications of institutional change use ex ante data on revealed behavior under status quo institutions to predict ex post consequences of policy change. Most of this empirical analysis and policy simulation relies upon aggregate production function specifications with varying degrees of complexity and functional flexibility.

This article highlights a fundamental problem with using aggregated ex ante production functions for such predictions. We show that if output compositions are shaped by decisions (e.g., where and when to fish) that are influenced by the institutional context of the fishery, then the global production set may be selectively and sparsely sampled. The implication is that there may be precious little data with which to identify important aspects of the production frontier, such as the marginal rates of transformation or elasticities of substitution, in the very regions most relevant after the policy change. Indeed, our simulations present situations where a significant portion of the output transformation frontier is completely unidentified non-parametrically. The result is that estimates using these ex ante data in flexible functional forms, such as the translog or generalized Leontief, may be inadequate for informing policy makers about ex post output transformation possibilities under alternative institutional conditions. ${ }^{24}$

We have shown that the institutionally filtered data-generating process we are likely to observe under ex ante conditions may yield a statistically estimated frontier that mimics the global frontier, to a local approximation, at the mean of ex ante conditions. But this is of limited utility when the task is to predict policy changes under non-local ex post conditions- those where predictive insight is most needed. This is most readily seen in figure 3 . The two lower graphs represent an ex ante situation in which species one and two are valuable targeted species. Suppose that regulators wish to introduce a policy that significantly reduces the catch of species one through a tax on bycatch of $y_{1}$ (shifting the price from 2 to -1 ) or an equivalent system of vessel-specific bycatch quotas. Economists attempting to predict the effects of this policy change would only have data gathered under the ex ante regulatory structures depicted in the two lower graphs. It is plain that any inference drawn from the data alone suggest that the marginal rate of transformation of $y_{1}$ for $y_{2}$ would be large and positive for low levels of $y_{1}$, signifying that large amounts of $y_{2}$ must be given up for a reduction in $y_{1}$. This could lead to dire predictions of the cost of the policy in terms of reduced catch and profits. But in the actual ex post situation, the species ratios that would emerge would be like those in the upper graphs of figure 3-revealing hitherto unexplored possibilities for targeting of $y_{2}$, even in the face of

24. Although our application is to fisheries with its own specialized production processes, the problem we address is potentially relevant in any case where important, context-specific micro-margins of choice are subsumed into aggregates within production, cost, and revenue functions. The implications of lumping policy-relevant behavioral margins into aggregated models of behavior have been discussed extensively in the policy evaluation (Heckman 2000, 2010; Wolpin 2013) and macroeconomic (Lucas 1976) literature. In particular, Lucas (1976) points out that if neglected behavioral margins are impacted by a policy change, then there is no reason to expect that aggregate relationships that take the former behavioral responses for granted within reduced-form parameters will be stable to interventions in management. 
mandated reductions in $y_{1}$. In practice, whether any particular analysis generates such dramatically false predictions will depend, in part, on the extrapolative properties of the particular functional form and estimator. One can imagine scenarios in which a parametric estimate using ex ante data manages to achieve a reasonable approximation to the output transformation frontier under ex post conditions. However, if the situation is anything like that in figure 3 , this fortunate result will be the lucky outcome of extrapolation rather than anything gained from the data, which are completely uninformative about ex post production possibilities.

The results from our simulation exercise are even more troubling because of the very simplicity of the model that generated them. We use a purposefully streamlined model to demonstrate that even in the extreme short run, when other factors known to be subject to institutional change are held constant, the empirical production set may be poorly identified and thus have little predictive ability. Adding complexity to the technology and more richness to the decision space is likely to make the fundamental policy variance problem even more severe.

While we abstract from many details of real-world fisheries, our findings are supported by recent empirical work on the introduction of harvesting cooperatives to the Bering Sea/Aleutian Islands groundfish trawl fishery in 2008. The introduction of harvester cooperatives discretely increased the shadow cost of Pacific halibut bycatch as cooperative members adopted an individual quota system for halibut bycatch. The change in shadow costs of bycatch changed spatiotemporal fishing effort (Abbott, Haynie, and Reimer 2015) and, as a result, shifted the estimated fishing production frontier, causing a sudden reduction in halibut bycatch with comparatively minor losses to target catch (Reimer, Abbott, and Haynie 2017). Importantly, the change in the revealed target/bycatch substitution occurred in the time frame of a single season within a stable technology and without significant changes to vessel or gear. Fishermen primarily altered their catch composition through redeployment of their gear in space and time (Abbott, Haynie, and Reimer 2015). This empirical evidence is consistent with our contention that fishermen are likely to adapt to market and management conditions, at least initially, by the redeployment of their fishing gear in space and time, making the Lucas critique a disturbingly relevant shortrun phenomenon for applied fisheries economics.

How can fisheries economists conduct their analyses to improve the potential for accurate ex ante policy prediction? There is no panacea. However, progress may arise from a return to first principles: all economic models involve a characterization of (1) the production technology and (2) an agent's decision-making process (i.e., profit or utility maximization), conditional on market and institutional parameters and constraints. Accurately predicting the impacts of a novel policy change requires that the parameters of each model component be invariant to the change itself - that they be 'structural' with respect to the intended policy counterfactual space (Heckman and Vytlacil 2007). In terms of the production technology, this requires identification of production parameters that are truly 'technical' in nature, as opposed to conflating the intersection of technology and behavioral responses to market and institutional constraints. Specific prescriptions will inherently be context-specific, but will generally require that the production process be modeled at a sufficiently deep level that all important policy-endogenous decision margins are explicitly included.

Developing a model for ex ante policy prediction can be broken into two components: (1) identifying the economic structure driving fisher behavior; and (2) identifying the policy-invariant parameters of the production technology. In our simple short-run model, policy acts directly on the spatial choices of fishermen, while other margins of behavior are held fixed. Therefore, the policy- 
invariant technical parameters are contained within the local production techniques that determine location-specific catch rates, and the policy-relevant decision margins include the placement of gear over space and time in response to the economic and policy parameters $p_{1}, p_{2}$, and $\beta$. With such complete knowledge of the technical and economic structure of the model, the process for ex ante policy prediction is straightforward in principle: impute the changes in shadow prices consistent with a particular institutional change (e.g., Fulginiti and Perrin 1993; Squires 1994), ${ }^{25}$ and then use the behavioral model to simulate behavior, catch outcomes, and profits under the counterfactual policy.

Unfortunately, the real world of policy prediction is considerably less straightforward. In practice, analysts do not know local production technologies or behavioral motives so precisely, but must infer them from fisheries-dependent data. There are strong precedents for structural economic modeling of fisher behavior: for example, predicting the behavioral response of fishermen to the implementation of area closures (Smith and Wilen 2003) or individual output (Reimer, Abbott, and Wilen 2014), input (Dowling et al. 2013; Mangel, Dowling, and Arriaza 2013), or habitat (Holland and Schnier 2006) quotas. If these models approximate the decision processes of fishers under a range of conditions, including the ex ante policy scenarios, then they have the potential to identify policy-invariant relationships. However, they do so at the cost of requiring large amounts of detailed micro-behavioral data as well as a willingness to impose strong a priori restrictions on the decision process of fishermen, such as stochastic dynamic programming (e.g., Huang and Smith 2014). Which assumptions to impose on fisher behavior must ultimately be assessed by the out-of-sample predictive ability of competing models (McCracken 2000 ); in some cases structural models may need to incorporate findings from behavioral economics to yield more robust predictions (Chetty 2015). In addition, interviews with fishermen or contingent-behavior experiments may provide researchers with valuable ancillary data to help them select models that are robust across the necessary range of institutional circumstances.

A second difficulty of predicting the impacts of institutional change is that the definition and parameters of the local production technologies are often unknown. Parameter estimates of local production techniques are generally hampered by a lack of sufficient data coverage for all possible production techniques available to fishermen. This is particularly the case when policy-invariant production techniques are numerous and finely differentiated or prone to nonstationarity (e.g., variations in CPUE at fine spatial and temporal resolutions) - leaving some local production techniques without sufficient historical observations for parameter estimation. The problem, however, is beyond one of mere data sparsity. Instead, it is one of selective data sparsity induced by the selective sampling of fishermen under the incentives of a given set of institutions. While previous work has made progress in accounting for selection bias in the estimation of the parameters of local production techniques due to profit maximization on the part of vessels (e.g., Campbell 1991), it does not address institutionally driven selection effects that hamper the ability to identify underrepresented areas of the global production set. Securing larger, more high-resolution datasets under existing management institutions will be, at best, a partial solution under strong institutionally driven selection. The reason is that the asymptotics for regions of the global production set that are distant from the mean will converge slower than $\sqrt{N}$ due to selection and will, therefore, yield noisy estimates without strong structural assumpchoices.

25. Other management constraints (e.g., spatial closures) may be best incorporated as direct constraints on fishermen's 
tions. In such situations, interpolation and/or imputation methods may be required to fill in the "holes" created by sparse sampling of certain areas of the production set (e.g., Walters 2003; Campbell 2004; Carruthers et al. 2014). Management may aid in this process by filling the data gaps left by this sparsity by strategically shifting stock assessment surveys to less heavily fished areas or time frames, or by providing incentives for fishermen to fish in these areas or times, either through relaxation of regulations (as with experimental fishing permits) or outright subsidization.

In the words of the sage: "prediction is very difficult, especially if it's about the future."26 However, the need to predict the impacts of significant fishery policy changes will not go away. Truly structural models - models whose parameters exhibit policy invariance and correspondingly robust predictions under a wide array of biological, economic and institutional shocks - are likely a pipedream. Our models are always incomplete, and our structural parameters are ultimately reduced forms. Our data pass through "institutional filters," providing limited information about production technology under counterfactual management. Considerable assumptions about technology and behavior are necessary to span the chasm between the data and the new scenario. However, researchers can take some comfort in the fact that all that is really needed in any given situation is a model that is "structural enough" to generate robust predictions for the policies and time horizons under immediate consideration (Heckman and Vytlacil 2007). Achieving the right balance of data and a priori assumptions to this end is likely to remain something of an "art" to fisheries economists, but it is a craft that can (and should) be sequentially refined through testing of our predictions against cold reality. To do otherwise, is to risk drawing fragile inferences on the basis of an incongruous past.

\section{REFERENCES}

Abbott, J. K., and A. C. Haynie. 2012. "What Are We Protecting? Fisher Behavior and the Unintended Consequences of Spatial Closures as a Fishery Management Tool." Ecological Applications 22(3):762-77.

Abbott, J. K., A. C. Haynie, and M. N. Reimer. 2015. "Hidden Flexibility: Institutions, Incentives and the Margins of Selectivity in Fishing." Land Economics 91(1):169-95.

Abbott, J. K., and J. E. Wilen. 2010. "Voluntary Cooperation in the Commons? Evaluating the Sea State Program with Reduced Form and Structural Models." Land Economics 86(1):131-54.

_ 2011. "Dissecting the Tragedy: A Spatial Model of Behavior in the Commons." Journal of Environmental Economics and Management 62(3):386-401.

Alvarez, A., and P. Schmidt. 2006. "Is Skill More Important Than Luck in Explaining Fish Catches?" Journal of Productivity Analysis 26(1):15-25.

Anderson, L. G. 1976. "The Relationship between Firm and Fishery in Common Property Fisheries." Land Economics 52(2):179-91.

Branch, T. A., and R. Hilborn. 2008. "Matching Catches to Quotas in a Multispecies Trawl Fishery: Targeting and Avoidance Behavior under Individual Transferable Quotas." Canadian Journal of Fisheries and Aquatic Sciences 65(7):1435-46.

Campbell, H. F. 1991. "Estimating the Elasticity of Substitution between Restricted and Unrestricted Inputs in a Regulated Fishery: A Probit Approach.” Journal of Environmental Economics and Management 20 (3):262-74. 
Campbell, R. A. 2004. "CPUE Standardisation and the Construction of Indices of Stock Abundance in a Spatially Varying Fishery Using General Linear Models." Fisheries Research 70(2-3):209-27.

Carruthers, T. R., A. E. Punt, C. J. Walters, A. MacCall, M. K. McAllister, E. J. Dick, and J. Cope. 2014. "Evaluating Methods for Setting Catch Limits in Data-Limited Fisheries." Fisheries Research 153:48-68.

Chetty, R. 2015. "Behavioral Economics and Public Policy: A Pragmatic Perspective." The American Economic Review Papers and Proceedings 105(5):1-33.

Clark, C. W. 1973. "Profit Maximization and the Extinction of Animal Species." The Journal of Political Economy 81(4):950-61.

Clark, C. W., and G. R. Munro. 1975. “The Economics of Fishing and Modern Capital Theory: A Simplified Approach." Journal of Environmental Economics and Management 2(2):92-106.

Coelli, T. J., D. S. Prasada Rao, C. J. O’Donnell, and G. E. Battese. 2005. An Introduction to Efficiency and Productivity Analysis. 2nd ed. New York: Springer.

Copes, P. 1986. “A Critical Review of the Individual Quota as a Device in Fisheries Management.” Land Economics 62(3):278-91.

Crutchfield, J. A., and A. Zellner. 1961. Economic Aspects of the Pacific Halibut Fishery. Vol. 1, Fishery Industrial Research. Washington, DC: US Department of the Interior.

Cunningham, S., and D. J. Whitmarsh. 1980. "Fishing Effort and Fisheries Policy.” Marine Policy 4(4):30916.

Curtis, R. E., and R. L. Hicks. 2000. “The Cost of Sea Turtle Preservation: The Case of Hawaii’s Pelagic Longliners.” American Journal of Agricultural Economics 82(5):1191-7.

Diewert, W. E. 1974. "Functional Forms for Revenue and Factor Requirements Functions." International Economic Review 15(1):119-30.

Dowling, N. A., C. Wilcox, M. Mangel, and S. D. Pascoe. 2013. "Assessing Opportunity and Relocation Costs of Marine Protected Areas Using a Behavioural Model of Longline Fleet Dynamics." Fish and Fisheries 13(2):139-57.

Dupont, D. P. 1991. “Testing for Input Substitution in a Regulated Fishery.” American Journal of Agricultural Economics 73(1):155-64.

Eales, J., and J. E. Wilen. 1986. "An Examination of Fishing Location Choice in the Pink Shrimp Fishery." Marine Resource Economics 2(4):331-51.

Färe, R., S. Grosskopf, D.-W. Noh, and W. Weber. 2005. "Characteristics of a Polluting Technology: Theory and Practice." Journal of Econometrics 126(2):469-92.

Felthoven, R. G. 2002. "Effects of the American Fisheries Act on Capacity, Utilization and Technical Efficiency.” Marine Resource Economics 17(3):181-206.

Felthoven, R. G., W. C. Horrace, and K. E. Schnier. 2009. "Estimating Heterogeneous Capacity and Capacity Utilization in a Multi-Species Fishery." Journal of Productivity Analysis 32(3):173-89.

Felthoven, R. G., and C. J. Morrison Paul. 2004. "Multi-Output, Nonfrontier Primal Measures of Capacity and Capacity Utilization.” American Journal of Agricultural Economics 86(3):619-33.

Flores-Lagunes, A., W. C. Horrace, and K. E. Schnier. 2007. "Identifying Technically Efficient Fishing Vessels: A Non-Empty, Minimal Subset Approach.” Journal of Applied Econometrics 22(4):729-45.

Frisch, R. 1964. The Theory of Production. Dordrecht-Holland: D. Reidel Publishing Company.

Fulginiti, L., and R. Perrin. 1993. “The Theory and Measurement of Producer Response under Quotas.” The Review of Economics and Statistics 75(1):97-106.

Gordon, H. S. 1954. "The Economic Theory of a Common-Property Resource: The Fishery." The Journal of Political Economy 62(2):124-42.

Griffin, J. M. 1978. "Joint Production Technology: The Case of Petrochemicals.” Econometrica 46(2):37996.

Hannesson, R. 1983. "Bioeconomic Production Function in Fisheries: Theoretical and Empirical Analysis." Canadian Journal of Fisheries and Aquatic Sciences 40(7):968-82. 
Haynie, A. C., R. L. Hicks, and K. E. Schnier. 2009. "Common Property, Information, and Cooperation: Commercial Fishing in the Bering Sea." Ecological Economics 69(2):406-13.

Heckman, J. J. 2000. "Causal Parameters and Policy Analysis in Economics: A Twentieth Century Retrospective." Quarterly Journal of Economics 115(1):45-97.

- 2010. "Building Bridges between Structural and Program Evaluation Approaches to Evaluating Policy.” Journal of Economic Literature 48(2):356-98.

Heckman, J. J., and E. J. Vytlacil. 2007. "Econometric Evaluation of Social Programs, Part I: Causal Models, Structural Models and Econometric Policy Evaluation.” In Handbook of Econometrics, ed. J. Heckman and E. Leamer, Vol. 6B, 4779-874. New York: Elsevier.

Hicks, R. L., and K. E. Schnier. 2006. “Dynamic Random Utility Modeling: A Monte Carlo Analysis.” American Journal of Agricultural Economics 88(4):816.

—. 2008. "Eco-Labeling and Dolphin Avoidance: A Dynamic Model of Tuna Fishing in the Eastern Tropical Pacific." Journal of Environmental Economics and Management 56(2):103-16.

Holland, D. S., and K. E. Schnier. 2006. "Individual Habitat Quotas for Fisheries." Journal of Environmental Economics and Management 51(1):72-92.

Holland, D. S., and J. G. Sutinen. 2000. "Location Choice in New England Trawl Fisheries: Old Habits Die Hard." Land Economics 76(1):133-49.

Horrace, W. C., and K. E. Schnier. 2010. "Fixed-Effect Estimation of Highly Mobile Production Technologies." American Journal of Agricultural Economics 92(5):1432-45.

Hu, S. C. 1972. "Putty-Putty Versus Putty-Clay: A Synthesis." International Economic Review 13(2):324-41.

Huang, L., and M. D. Smith. 2014. "The Dynamic Efficiency Costs of Common-Pool Resource Exploitation." The American Economic Review 104(12):4071-103.

Jensen, C. L. 2002. "Applications of Dual Theory in Fisheries: A Survey.” Marine Resource Economics 17 (4):309-34.

Johansen, L. 1959. "Substitution Versus Fixed Production Coefficients in the Theory of Economic Growth: A Synthesis." Econometrica 27(2):157-76.

Jones, C. I. 2005. “The Shape of Production Functions and the Direction of Technical Change.” The Quarterly Journal of Economics 120(2):517-49.

Kirkley, J. E., and D. Squires. 1998. "Characterizing Managerial Skill and Technical Efficiency in a Fishery." Journal of Productivity Analysis 9(2):145-60.

Kirkley, J. E., D. Squires, and I. E. Strand. 1995. "Assessing Technical Efficiency in Commercial Fisheries: The Mid-Atlantic Sea Scallop Fishery.” American Journal of Agricultural Economics 77(3):686-97.

Kirkley, J. E., and I. E. Strand. 1988. "The Technology and Management of Multi-Species Fisheries." Applied Economics 20(10):1279-92.

Lian, C., R. Singh, and Q. Weninger. 2010. "Fleet Restructuring, Rent Generation, and the Design of Individual Fishing Quota Programs: Empirical Evidence from the Pacific Coast Groundfish Fishery.” Marine Resource Economics 24(4):329-59.

Lucas, R. E. 1976. "Econometric Policy Evaluation: A Critique." In The Phillips Curve and Labor Markets, Carnegie-Rochester Conference Series on Public Policy, ed. K Brunner and A.H. Meltzer, 19-46. Amsterdam: North Holland.

Mangel, M., N. A. Dowling, and J. L. Arriaza. 2013. "The Behavioral Ecology of Fishing Vessels: Achieving Conservation Objectives through Understanding the Behavior of Fishing Vessels." Environmental and Resource Economics 61(1):71-85.

McCracken, M. W. 2000. “Robust Out-of-Sample Inference." Journal of Econometrics 99(2):195-223.

McFadden, D. 1978. "Cost, Revenue, and Profit Functions." In Production Economics: A Dual Approach to Theory and Applications, ed. M. Fuss and Daniel McFadden, Vol. 1, 2-109. Amsterdam: North-Holland.

Mistiaen, J. A., and I. E. Strand. 2000. "Location Choice of Commercial Fishermen with Heterogeneous Risk Preferences.” American Journal of Agricultural Economics 82(5):1184. 
Pascoe, S., P. Koundouri, and T. Bjørndal. 2007. "Estimating Targeting Ability in Multi-Species Fisheries: A Primal Multi-Output Distance Function Approach." Land Economics 83(3):382-97.

Pascoe, S., A. E. Punt, and C. M. Dichmont. 2010. "Targeting Ability and Output Controls in Australia's Multi-Species Northern Prawn Fishery." European Review of Agricultural Economics 37(3):313-34.

Pearse, P. H., and J. E. Wilen. 1979. "Impact of Canada's Pacific Salmon Fleet Control Program." Journal of the Fisheries Board of Canada 36(7):764-9.

Reimer, M., J. K. Abbott, and J. E. Wilen. 2014. "Unraveling the Multiple Margins of Rent Generation from Individual Transferable Quotas.” Land Economics 90(3):538-59.

Reimer, M. N., J. K. Abbott, and A. C. Haynie. 2017. "Empirical Models of Fishing Production: Conflating Technology with Incentives?” Marine Resource Economics 32(2):169-90.

Rothschild, B. J. 1972. "An Exposition on the Definition of Fishing Effort." Fishery Bulletin 70(3):671-9.

Sanchirico, J. N., D. S. Holland, K. Quigley, and M. Fina. 2006. "Catch-Quota Balancing in Multispecies Individual Fishing Quotas.” Marine Policy 30(6):767-85.

Schaefer, M. B. 1954. "Some Aspects of the Dynamics of Populations Important to the Management of Commercial Marine Fisheries." Bulletin of the Inter-American Tropical Tuna Commission 1(2):25-56.

Scott, A. D. 1955. “The Fishery: The Objectives of Sole Ownership." The Journal of Political Economy 63 (2):116-24.

Shephard, R. W. 1970. Theory of Cost and Production Functions. Princeton: Princeton University Press.

Shumway, C. R., R. D. Pope, and E. K. Nash. 1984. "Allocatable Fixed Inputs and Jointness in Agricultural Production: Implications for Economic Modeling.” American Journal of Agricultural Economics 66 (1):72-8.

Smith, M. D. 2012. “The New Fisheries Economics: Incentives across Many Margins.” Annual Review of Resource Economics 4:379-429.

Smith, M. D., J. Lynham, J. N. Sanchirico, and J. A. Wilson. 2010. "Political Economy of Marine Reserves: Understanding the Role of Opportunity Costs." Proceedings of the National Academy of Sciences of the United States of America 107(43):18300-5.

Smith, M. D., and J. E. Wilen. 2003. "Economic Impacts of Marine Reserves: The Importance of Spatial Behavior." Journal of Environmental Economics and Management 46(2):183-206.

Smith, V. K., and W. J. Vaughan. 1979. "Some Limitations of Long-Run Production Modeling with PseudoData." The Journal of Industrial Economics 28(2):201-7.

Squires, D. 1987a. "Fishing Effort: Its Testing, Specification, and Internal Structure in Fisheries Economics and Management." Journal of Environmental Economics and Management 14(3):268-82.

. 1987b. "Public Regulation and the Structure of Production in Multiproduct Industries: An Application to the New England Otter Trawl Industry." The Rand Journal of Economics 18(2):232-47.

. 1994. "Firm Behavior under Input Rationing." Journal of Econometrics 61(2):235-57.

Squires, D., M. Alauddin, and J. E. Kirkley. 1994. "Individual Transferable Quota Markets and Investment Decisions in the Fixed Gear Sablefish Industry." Journal of Environmental Economics and Management 27(2):185-204.

Squires, D., and J. E. Kirkley. 1991. "Production Quota in Multiproduct Pacific Fisheries." Journal of Environmental Economics and Management 21(2):109-26.

_. 1995. "Resource Rents from Single and Multispecies Individual Transferable Quota Programs." ICES Journal of Marine Science 52(2):153-64.

- 1996. "Individual Transferable Quotes in a Multiproduct Common Property Industry." Canadian Journal of Economics 29(2):318-42.

. 1999. "Skipper Skill and Panel Data in Fishing Industries." Canadian Journal of Fisheries and Aquatic Sciences 56(11):2011-8.

Squires, D., and N. Vestergaard. 2013a. "Technical Change and the Commons." Review of Economics and Statistics 95(5):1769-87. 
168 | MARINE RESOURCE ECONOMICS | VOLUME 32 NUMBER 2 2017

. 2013b. "Technical Change in Fisheries." Marine Policy 42:286-92.

Turner, M. A. 1997. "Quota-Induced Discarding in Heterogeneous Fisheries." Journal of Environmental Economics and Management 33(2):186-95.

Walters, C. 2003. "Folly and Fantasy in the Analysis of Spatial Catch Rate Data." Canadian Journal of Fisheries and Aquatic Sciences 60(12):1433-6.

Weninger, Q. 2008. "Economic Benefits of Management Reform in the Gulf of Mexico Grouper Fishery: A Semi-Parametric Analysis.” Environmental and Resource Economics 41(4):479-97.

Weninger, Q., and J. R. Waters. 2003. "Economic Benefits of Management Reform in the Northern Gulf of Mexico Reef Fish Fishery.” Journal of Environmental Economics and Management 46(2):207-30.

Wilen, J. E. 1979. "Fisherman Behavior and the Design of Efficient Fisheries Regulation Programs." Journal of the Fisheries Board of Canada 36(7):855-8.

- 1988. "Limited Entry Licensing: A Retrospective Assessment." Marine Resource Economics 5 (4):289-311.

Wolpin, K. I. 2013. The Limits of Inference without Theory. Cambridge, MA: MIT Press. 